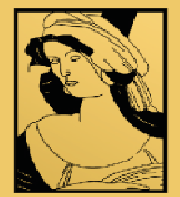

\title{
ALEXANDRIA
}

Revista de Educação em Ciência e Tecnologia

ALEXANDRIA

\section{Escritas em Passagens, Investigadores Infantes Matemáticas Brincantes}

\section{Writing in Passages, Infantes Researchers, Mathematics Playing}

\section{Cláudia Regina Flores ${ }^{\mathrm{a}}$; Mônica Maria Kerscher ${ }^{\mathrm{a}}$; Bruno Moreno Francisco ${ }^{\mathrm{b}}$.}

a Departamento de Metodologia de Ensino, Universidade Federal de Santa Catarina, Florianópolis, Brasil claudia.flores@ufsc.br, monicakerscher@gmail.com

b Secretaria Municipal de Educação, Florianópolis, Brasil - bmoreno.prof@gmail.com

\section{Palavras-chave:}

Pesquisa. Escrita.

Experiência. Infância.

Keywords:

Research. Writing.

Experience. Infancy.
Resumo: Este artigo é uma escrita em passagem que se debruça sobre investigadores infantes que brincam com um modo de investigar e um modo de escrever: uma escrita de pesquisa e uma pesquisa de escrita. Abrimo-nos à poesia para fazer, falar e escrever pesquisas em educação matemática, buscando tecer um modo de escrita que oferece mais pensamentos do que fundamentos. Pensamentos que, em seu devir, podem não ser nada, embora seja apenas deste modo que estamos determinados a escrever uma pesquisa dita acadêmica.

Abstract: This article is written in passing that look at infant researchers who play with a way of researching and a way of writing this: a written of research and a research of written. We open ourselves to poetry to do, to tell and to write research in mathematics education, seeking to weave a writing mode that offers more thoughts than foundations. Thoughts that in its beginning may be nothing, although it is only in this way that we are determined to write a research so-called academic. 


\section{Introdução ou algum começo para começar}

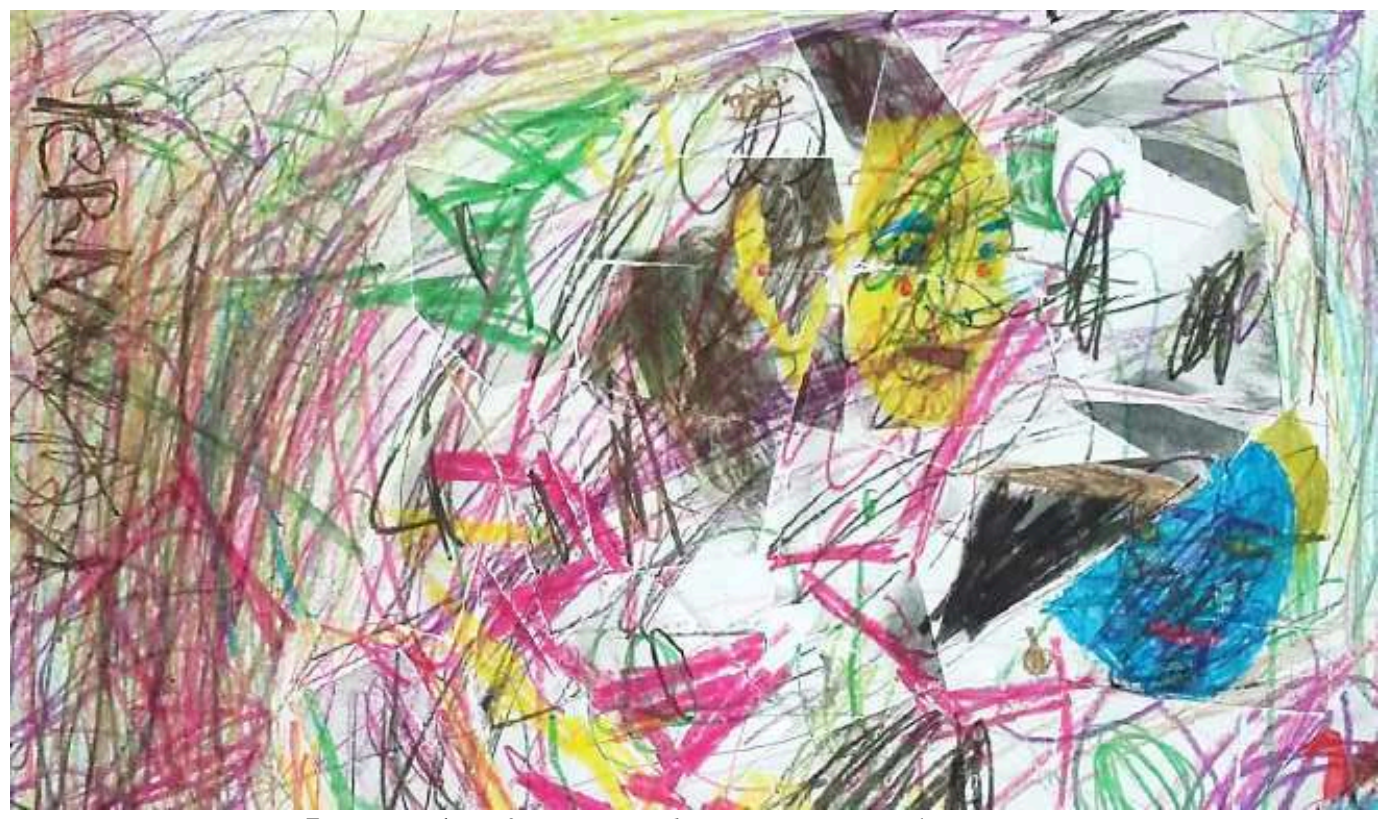

Imagem 1 - oficina-com-des-re-tra-tos: Todas as cores.

Fonte: Francisco (2017, p. 213)

Este texto, antes de escrito, não é, em nós, mais que um aflito, silêncio, delírio, página em branco. Este texto, antes de escrito, antes de ser, é a possibilidade do que não foi dito, do que está por dizer. Mas antes de dizê-lo, não se sabe, uma vez que o que é dito não existia e o que diz pode ser que não diria. É que só o que não se sabe é escrita (GULLAR, 2015). Aqui escrevemos outro texto ${ }^{1}$, criamos uma escrita outra de nossas escritas. Não é revelar o que já estava escrito. Nem explicar essas escritas, mas um desexplicar. É que inventamos o que dizer, e que, só ao dizê-lo, vamos saber o que precisa dizer, ou pode ser dito, ou ainda, o que a vida experimentada permite (GULLAR, 2015).

Aqui um texto composto de restos, imagens, algumas palavras ou coisas, pois que "palavras também são coisas - coisa volátil que pegamos no ar com a boca quando falamos" (LISPECTOR, 1999, p. 104). “[...] Ao escrever misturamos tintas, umas nas outras, e nasce uma nova cor" (LISPECTOR, 1999, p. 71). As cores que se misturam (Imagem 1), renascem, colorem e descolorem na tinta de uma escrita. Assim, uma escrita desenhada nas misturas das cores.

Tintas que já são habitadas, invadidas e confundidas por outras cores. Cores vibrantes, intensas, cintilantes, suaves, foscas, quentes, frias, que se entrecruzam, se atravessam, se tingem formando e desformando este texto. Daí que este texto se escreve, se inscreve ou

\footnotetext{
${ }^{1}$ O presente trabalho foi realizado com o apoio da CAPES (Coordenação de Aperfeiçoamento de Pessoal de Nível Superior), na modalidade Bolsa Estágio Sênior no Exterior para a primeira autora, e Bolsa de Mestrado, para os demais autores. O trabalho tem o apoio da CAPES/PROEX.
} 
descreve, pois é escrito a seis mãos - ou mais - e tantas cores que se misturam e formam isso que se pode chamar de um outro texto, um texto outro. Um artigo colorido, afinal, pois achamos interessante brincar com essa ideia de cores no texto ${ }^{2}$. "Às vezes, viajamos dentro de bolhas de sabão, misturando-nos ao jogo das cores de suas cúpulas até que se rompam e irrompam em nós. Perdemo-nos nas cores, nos céus, no jardim, em um livro, na poesia e em nós" (BENJAMIN, 2012, p. 102).

Desta forma, tem hora que somos quando um pequeno príncipe. E sendo um, podemos habitar o menor dos planetas, conversar com seres estranhos e imaginar outros mundos. $\mathrm{Ou}$ tem hora que somos quando vento e podemos levar conosco os ciscos de poeira e as folhas secas das árvores. Assim: tem hora que somos quando crianças. E tudo pode ser outra coisa e virar uma brincadeira. Hoje nós estamos quando infantes. E em um ato in-fante podemos inventar outras fórmulas para pesquisar e escrever nossos achados em pesquisa na educação matemática (FLORES, 2017). Agora nós resolvemos voltar quando infantes por um gosto de voltar, como quem aprecia ir às origens de uma coisa ou de um ser. Então, agora nós estamos quando infantes (BARROS, 2006).

Daí que algo se põe ou interpõe: como produzir uma escrita acadêmica que narre a experiência do processo de pesquisar, aprender e ensinar matemática? É possível fazer, dizer e escrever uma experiência em educação matemática sem capturá-la e aprisioná-la na representação e na significação? Para isso, pensamos, seria preciso centrar a atenção na ideia de experiência na perspectiva do isso que nos passa, isso que nos acontece (LARROSA, 2016). O que significa considerar a pesquisa (em educação matemática) como processo, como produção de processos, e como experiência, um exercício de pensar. Uma investigação que faça vibrar os limiares de um processo de encontro com/entre as pessoas, as coisas, as crianças, a matemática, os investigadores, os professores e a arte. Que abra as coisas para suas multiplicidades e intensidades, que trabalhe mais nas misturas, contágios e interações dos processos, e menos em uma suposta pureza dos métodos e dos sujeitos. Que se abra em alegria.

Nesse movimento lançamos uma suspeita, ou melhor, um convite para suspeitar. Suspeitar que pode haver outros modos de investigação, outras ideias, outras coisas, de que pode haver outras formas de escrita de dissertações, teses e artigos acadêmicos, outra língua, outra atitude, outra ética. E dessa suspeita deixar brotar outros modos de investigação e de escrita dessas investigações, nem sempre tão claros, evidentes, mas quase sempre como processos de criação. Então, se algo precisa ser dito sobre o que este texto aqui pretende,

\footnotetext{
${ }^{2}$ A princípio este texto foi escrito em cores, relacionando uma cor para cada autor e obra, os quais poderiam ser identificados na bibliografia ao final do texto. Contudo, por questões de normas acadêmicas, o texto precisou voltar a ser escrito na cor preta. Entretanto, ainda assim, ele se colore pela multiplicidade de colores, como o artista colore sua própria paleta.
} 
podemos dizer que ele despretende, pois o que ele quer é deixar vibrar escritas em passagens, investigadores infantes e matemáticas brincantes.

Uma escrita em passagem por investigadores infantes que brincam com um modo de investigar e um modo de escrever. Decidimos contar nossas experiências investigativas a partir de passagens e, nelas, ensaiar uma escrita não mais dogmática, porém, mais poética. Uma escrita para pulsar uma experiência singular de afirmação da diferença nos espaços da sala de aula de matemática, e também, entre arte e educação, entre matemática e crianças e investigação, com problemas que ajudam a manter vivas as perguntas que movem o mundo e a vida no mundo. Escrevemos com poesia, poeticamente, inversamente. Escrevemos em português, mas entortamos a palavra, desprendemos relações. Escrevemos com poetas, com imagens da arte, com artistas, como poetas, como artistas, como infantes.

Daí um modo de escrita que não pressupõe um indivíduo, um lugar 'fixo', estável, ou regras fixas e dogmas a serem seguidos, mas que seja feito de experiência e de paixão. Um modo ficcional, um pacto de ficção, como aquele feito entre o escritor e o leitor, o pintor e o espectador. Um pacto não pela narração e descrição dos resultados de pesquisa, verdades universais e realidades intransponíveis, mas um pacto que permita deixar passar a emoção, perceber a ironia, expressar o transtorno, o delírio, a perda da razão e o não-saber. Por isso que agora somos quando poesia, e sendo poesia, o verbo enlouquece, a palavra desanda e a ideia pensa. Escolhemos pesquisar e escrever com poesia. E sendo poetas, não gostamos de palavras acostumadas, pois usamos as palavras para compor nossos silêncios, queremos a palavra que sirva na boca dos passarinhos (BARROS, 2006). Agora somos quando infantes, investigadores infantes. E, ao se colocar na infância das coisas, a matemática se transforma em forma dançante e se desforma na brincadeira.

\section{Como escrever um experimento ou como escrever o acontecimento}

Encontros, desencontros, que acontecem, nos acontecem. $\mathrm{O}$ acontecimento.

ISSo que nos passa nos movimenta, nos faz sair do lugar, coloca nossa posição em jogo. É um estar fora de posição. Uma ex-posição (MASSCHELEIN, 2008). Somos afetados pelos acontecimentos no percurso do pesquisar, do estar em pesquisa, com a pesquisa.

Isso que nos acontece faz tremer em nós sentidos, palavras. Palavras "inapropriadas, já que não conseguimos capturar tudo aquilo que se escreve ou se pensa quando se narra" (KERSCHER, 2017, p. 26, grifo da autora). Palavras incertas, instáveis, ressignificadas, inovadas, voláteis, palavras com poesia.

Isso que nos toca, faz-nos querer tecer uma escrita outra. Faz-nos querer sair do aprisionamento da escrita acadêmica padronizada, naturalizada e cientificizada. Faz-nos 
querer desviar dessa escrita que é arranjo para produzir efeitos de verdade, que é objetivada e que generaliza.

Mas, como narrar a intensidade trazida, soprada, remexida pelo vento que nos afeta em uma pesquisa-investigação com matemática e arte e crianças? Como escrever a experiência, uma vez que, na experiência, sempre existe algo de não sei o que me acontece? É preciso inventar outra língua, pois escrever essa experiência não pode ser pelo dogmatismo? Talvez sim. "Uma língua que nos permita viver no mundo, fazer a experiência do mundo e elaborar com outros o sentido (ou a ausência de sentido) do que nos acontece" (LARROSA, 2016, p. 65). Não uma língua com regras já determinadas pelo cientificismo da escrita acadêmica, majoritárias e tidas como universais, aquelas que já consideramos naturais e que dão veracidade e legitimação às nossas produções científico-acadêmicas. Ao contrário disso, inventamos na Língua uma nova língua, uma espécie de língua estrangeira nela própria, "que não se trata de outra linguagem, nem de um dialeto regional redescoberto, mas sim, de um devir-outro na língua, uma minoração dessa língua maior” (DELEUZE, 1997, p. 15). Em outras palavras, um delírio, pois, ao mesmo tempo que a ventania nos agita, ela nos faz rastejar, ir devagar, "impossibilitando nosso andar ereto" (FLORES, 2017, p. 174), até porque “não há andar ereto, nem nas coisas, nem na linguagem” (DELEUZE, 1997, p. 12).

Pensamos e escrevemos com os restos, pelo meio, no entre, com o menor, com o singular. Escrevemos com o sentir, o olhar, o escutar, o acaso, as cores, os ciscos da poeira, o vento e as folhas das árvores que se espalham pelo chão e formam outros caminhos, cobrindo buracos, fazendo montes, desenhando imagens no papel e na imaginação. Folhas jogadas ao vento (KERSCHER, 2017). Palavras-sopro. Escritas em passagem. Experiênciainvestigação.

De começos já começados, escrevemos tentando suportar o gaguejar e o estremecer das palavras sopradas pelo vento, fazendo-nos balançar, cambalear, tontear.

\begin{abstract}
Escrevemos palavras que são ditas com frequência, mas que, em nossas escritas, ganham outros e novos sentidos, pois fazemos coisas com as palavras. E dessas coisas, sentidos são dados ao que somos e ao que nos acontece, assim, o que vemos e o que sentimos são nomeados, e tais nomes são vistos e sentidos de alguma forma (LARROSA, 2016, p. 17).
\end{abstract}

"Entortar palavras. Envergá-las na língua" (FRANCISCO, 2017, p. 249). Voz dos olhos. Cheiro do tato. "Dormir feito aroma. Voz que também não fala" (GULLAR, 2008, p. 398). Barulho do silêncio do texto que nos invade.

Palavras são experimentadas com o acontecimento, com aquilo que nos passa. As palavras se mostram pelo riso, pela emoção, pelo incômodo, pela distração, pelos burburinhos, pela imaginação e por um pensamento que quer ser um sentir, uma alegria de viver, de estar ali. "Escrever como ler, como embaraçar(-se), desorientar(-se). Labirintamente..." (FRANCISCO, 2017, p. 37). Reunir "o encontro com seu desencontro, a 
passagem que não passa e que insiste em nos devolver ao ponto de partida, o caminho cujas pegadas devem voltar a serem pisadas" (SKLIAR, 2014a, p. 78). Assim, inventamos uma "prosa em "degraus", em três graus: um musical, em que ela é composta; um arquitetônico, em que ela é construída; e em um têxtil, em que ela é tecida" (BENJAMIN, 2012, p. 25). É

nesse sentido operacional que nossa escrita se manifesta realmente: compondo, construindo e tecendo. Agora tudo indica que esses "degraus" se abalam nas paisagens que nos tocam na pesquisa. Vinculados sempre um ao outro, em uma conformidade que é, ao mesmo tempo, vida e morte, composição e decomposição, construção e destruição, tecer e destecer... (des)ordeiramente. Na intensidade que comporta seu devir. Que comporta a abertura às insistências do mundo (FRANCISCO, 2017, p. 89-90, grifo do autor).

Prosamos-em-graus, portanto, com gostos, desgostos, ritmos, desvios, olhares, escutas, afetos, escolhas, idas e vindas, com o que se vive na pesquisa, com o pesquisar. Cada palavra se faz viva, carrega uma vida entre letras e linhas, com a escrita.

Em nossas investigações escritas, atrevemo-nos

a sentir os tecidos de uma rememoração, isto é, os cacos de uma atividade afetiva de memórias que incorporaram uma forma de experiência coletiva acerca dos preparativos, invencionáticas, produções e intervenção de oficinas. Atrevemos-nos, também, a sentir o canto do serrilho que impulsiona a fabricação de oficinas; atrevemo-nos a nos apoderar de memórias cintiladoras de instalações oficineiras e flamejantes nas crianças, com crianças, com um grupo descomparado de pesquisa ${ }^{3}$ (FRANCISCO, 2017, p. 85, grifo do autor).

Sentimos os mistérios da fulguração no silêncio do barulho para fazer falar as experiências, fazer tecer experiências de montações de oficinas com imagens e crianças, com imaginações de crianças, com crianças que dão a imaginar um pensar; do pensar matemática(s); da experiência matemática de crianças e com crianças... É que "a experiência não pode ser antecipada, não tem a ver com o tempo linear do planejamento, da previsão, da predição, esse tempo em que nada nos acontece, e sim, com o acontecimento do que não pode 'pre-ver', nem 'pre-escrever'” (LARROSA, 2016, p. 69, grifos do autor). O que não significa, entretanto, que não haja planejamento, objetivo, protocolos a seguir, mas antes disso, uma certa organização para que coisas aconteçam e possam ser comunicadas.

\section{..}

- Vocês receberam em mãos um kit, não foi? Uma caixinha, um pacotinho e, dentro dele, vários pedacinhos de papel. $\mathrm{O}$ que eu quero que vocês façam agora (?)...

- É o que vou falar, ó... Eu sei o que a gente vai ter que fazer. Vamos abrir o saquinho, "coisar" e pintar - disse Isadora.

- Vocês vão fazer uma montagem com essas pecinhas e eu quero ver o que vai sair daí. Certo? ... Ah, isso aqui não é um quebra-cabeça.

- Hum?! Hem?!

Isto: o espanto das crianças pela des-norma, pelo desquebrado quebra-cabeça. (FRANCISCO, 2017, p. 179) (Imagem 2).

\footnotetext{
${ }^{3}$ Grupo de Estudos Contemporâneos e Educação Matemática - GECEM/UFSC.
} 


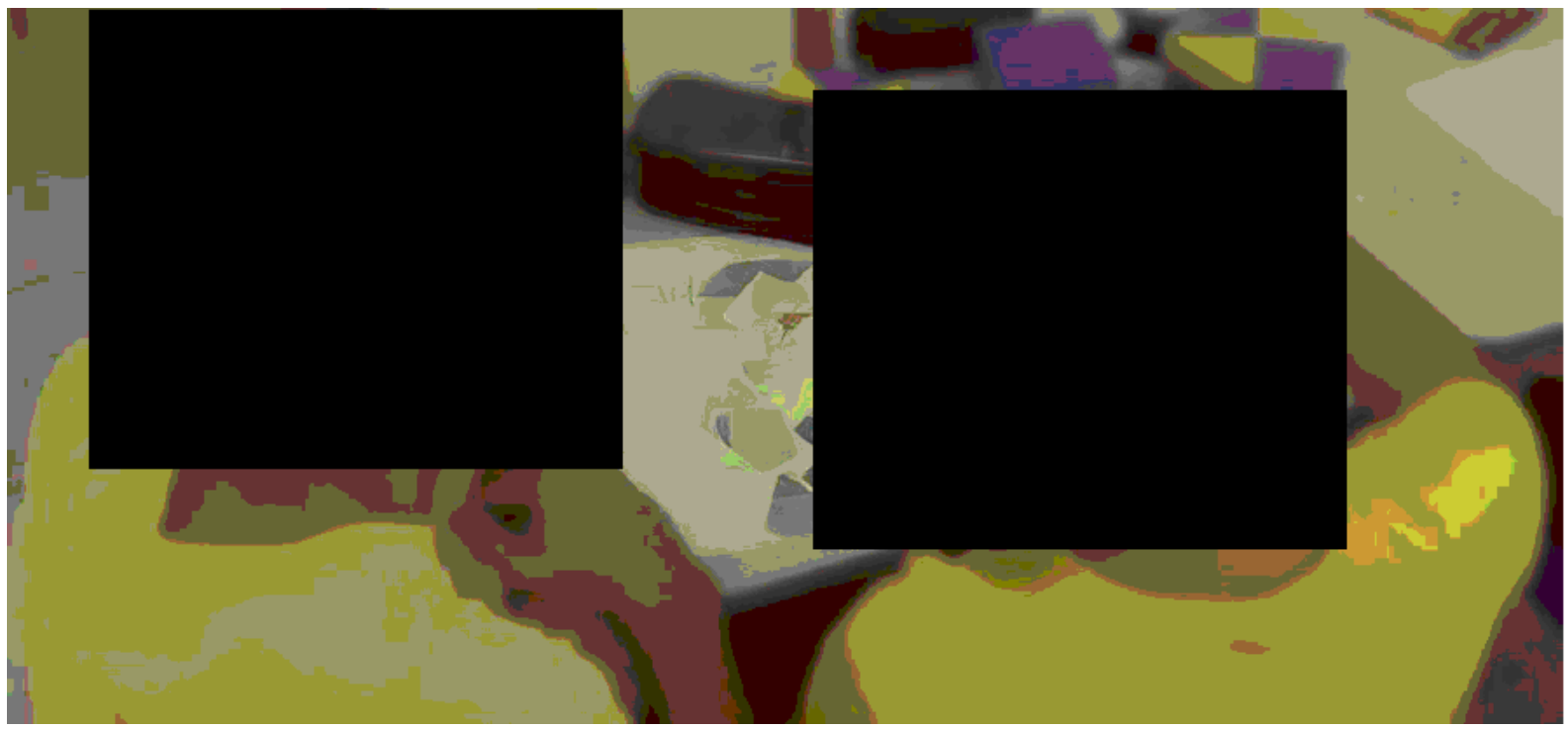

Imagem 2 - oficina-com-des-re-tra-tos: Eu entre tipos de meus.

Fonte: Francisco (2017, p. 209)

Até aqui, advertimos:

A mim, queixando da difícil espera de sentir o clamor e o calor da escrita.

Caí de cheio, em um duelo impensado, entre mim mesma e as palavras insistentemente.

Até aqui, confesso - diretamente às palavras:

- São hospedeiras do silêncio e da perturbação do corpo.

- São lágrimas para os olhos e fervuras para nossas entranhas.

- São amálgamas de doçura e azedume.

- São amigas que nos traem e inimigas que nos consolam.

- São arcos que fizeram da escrita alvo de suas flechas.

- São golpeadoras que nos dominam quando menos esperamos.

- São como prisões (FRANCISCO, 2017, p. 34).

- São como liberdade.

Pois que narrar o acontecimento é sempre um exercício da alteridade, um estar com o outro, entre o outro, onde há sempre um não-saber, um “"não sei o que me acontece', [...], 'não sei o que dizer', [...] 'não sei o que posso fazer'” (LARROSA, 2016, p. 69).

\section{Como escrever os sentidos e os significados ou como escrever aquilo que irrompe em nós}

Uma ventania chega em nós: balança, chacoalha, movimenta, paralisa. Isso que nos passa, em nós marca. As folhas das árvores se remexem, voam, fogem, se escondem, se rasgam. Nós nos remexemos, voamos, fugimos, nos escondemos. Redemoinhos se formam ao nosso redor, em nós. Mil folhas, sem folhas, desfolhadas. Há folhas-ideias que dançam com o vento, se perdem, nós as perdemos. Há folhas-ideias que vêm em nossa direção, passam por nós e nos arrebatam (KERSCHER, 2017). Irrompe em nós uma força intensiva. Mas quando isso nos acontece, como escrevemos o que nos passa?

Aqui uma escrita que é exercício de pensar, de estar, de experimentar, de sentir, de se afetar, de estranhar. É composição de um estilo com os efeitos e com os lampejos do que nos afeta. É exploração de estados inéditos de nós mesmos e do mundo. É caminhar com 
disposição a deixar-se levar, pelo vento, talvez, e quando o vento toca bem forte, agarrá-lo. É "tentativa de sensibilizar a língua para que ela trema e estremeça, e que esse terremoto abra fendas assustadoras nessa língua" (LISPECTOR, 1999, p. 87). É experiência da linguagem, em que aquilo que se tem experiência é a própria linguagem. É não falar tudo, não saber tudo e nem pensar tudo, mas pensar de novo e novamente. É, na impossibilidade de se expressar, criar significados, recuperar ideias, vasculhar funcionamentos, e narrar o que se experiencia (FLORES, 2017).

Há dois marços me dou conta de que no deserto e na história de O Pequeno Príncipe, com a qual estou envolvido, se (des)abotoam algumas coisas. É quando me lembro da primeira reunião de estudos - quando, possivelmente, saí de casa, peguei dois ou três ônibus e, de repente, me vi estrangeiro em outra cidade, e mais longe, em outro estado. Quando meus próprios olhos se viram imigrantes, caídos em um deserto pesquisativo. Aqui, ainda, me sinto desestabilizado. Descobri que emigrar faz parte desse modo de enfrentar a pesquisa, de comportar estrangeiramentos. Estrangeirar. O que está por vir? Quem? Há sempre um respingo de dúvida, instabilidade. Um incômodo e até uma chateação (FRANCISCO, 2017, p. $56)$.

E então, "me perco, me acho, perambulo, corro, paro, volto, pulo, dou voltas, sevirayoltaz. Passeio, saboreio, sinto, experimento, penso, penso de novo, e de novo, sempre a pensar. Encontro, desencontro, habito, me permito. Permito aberturas" (KERSCHER, 2017, p. 27). "Que idioma você fala? De onde eu venho, não é o mesmo que o seu. Do seu para o meu, por exemplo, sou alienígena que, de um modo ou de outro, sou estrangeiro, aquele que não pertence a este lugar, passageiro, viajante, de passagem” (FLORES, 2017, p. 172-173). “Às vezes, uma parte de mim é todo mundo, outra parte é ninguém, fundo sem fundo. Uma parte de mim pesa, pondera, outra parte, delira. Às vezes, uma parte de mim é só vertigem, outra parte, linguagem. Traduzir-se uma parte na outra parte - que é uma questão de vida ou morte - será arte?" (GULLAR, 2008, p. 293).

Como não se deixar tocar enquanto caminhamos cambaleantes por uma terra investigativa? Como, em um espaço com crianças e arte e matemática, poderíamos nos abrir à experiência, ao invés de nos fecharmos em experimento? Como sufocar a goela, parar o verbo de um nós, viventes com palavras, pelas palavras, pelos sentidos e não-sentidos, com o outro e sem o outro?

Mas eis que é o que se pede:

O presente trabalho parte do interesse de discutir matemática em relação com a arte num trabalho de oficinas com crianças, enquanto traçado de uma perspectiva a-pontual e mais atual dessa temática no âmbito da Educação Matemática. Apontual, pois se delineia distintamente daquela em que a matemática se simula na arte... (FRANCISCO, 2017, p. 46, grifo do autor).

Para quem entende as metodologias e os problemas de pesquisa dos contos acadêmicos, encontraria aí uma pitada de verdade, um tom de objetividade, de jeito de poder 
- um jeito de escrita que se sabe, de antemão, aonde nos arrastará, que resultados iremos obter. Um modo de estar fora de um campo minado, provavelmente. Fora de um texto em chamas. Mas não! Queremos um texto em chamas! Com esse efeito.

Há algo que fisga ali e aqui. Explode ao contato com as coisas. Talvez não tenha sentido no começo, não seja pedaço a ser considerado. Talvez, também, não se saiba de onde sai e nem onde vai chegar, nem mesmo se vai chegar a algum lugar. Mas algo irrompe e interrompe o pensamento. Insuspeitas vertentes da escrita se abrem. Perdemos o controle na turbulência e o texto já está em chamas, é chama. Chama-nos a escrever o que nos prende e nos surpreende com a vivência das palavras nas palavras. Dobramo-nos na escrita para desaprender velhas fórmulas. "Para desaprender é preciso voltar ao estado de infância" (FLORES, 2017, p. 184, grifo da autora).

Caminhamos como investigadores infantes e espiões cautelosos, "em meio a produções de processos movediços. Carregamos um leque em nosso bolso para, também, soprar o vento (caso ele diminua, ou até mesmo se dissipe) e fazer vibrar a intensidade que nos toca" (KERSCHER, 2017, p. 112). Pois, "escrever não encontra uma trajetória simples, despojada de labirintos, nem uma sequência que admita progressão ou culminação: a escrita é esse mistério que permanece escrevendo a si mesmo" (SKLIAR, 2014a, p. 126-127). E, entre tantos corredores labirínticos, habitados, seguimos por onde nos encontramos afetados pela brisa das sensibilidades, acariciamento dos afetos, formigamentos dos pensamentos e sopro das ideias, para compormos e embrenhar-nos em uma escrita (com oficinas e crianças e matemática e... e... e...) (KERSCHER, 2017).

\section{Como escrever o resultado ou como escrever o que está entre}

Ao nos passar a ventania, ela causa movimentos, desestabilidades, pulsações. É ao transitar no entre da ventania que algo acontece, nos acontece. É uma passagem que tem a ver com uma viagem, um caminho, um percurso, uma travessia, um deslocamento. É, portanto, na transitoriedade, na passagem, no passo, que compomos uma escrita, um modo de escrita. Pois somos balançados, e ao sermos balançados, movimentados, algo já mudou, nós já mudamos, e a escrita já não é a mesma. "Porque eu mudo, o mundo muda, e a escrita irrompe de onde menos se espera. Às vezes, cheirando à flor, às vezes, desatada no olor da fruta podre, que no podre se abisma" (GULLAR, 2008, p. 340).

Estar no entre é borrar fronteiras, esmaecer limites, indeterminar lugares. É habitar a dobra da onda. É acolher as multiplicidades. É percorrer uma fita de Möbius por uma linha, uma linha que ora parece estar dentro ora fora, mas que nunca está nem dentro (interior) e nem fora (exterior), embora esteja sempre na relação do dentro-fora. Desta forma, como 
escrever no "entre", no próprio espaço do "entre", na pesquisa com crianças e arte e matemática e sala de aula?

Colocamo-nos em exercício de pensar e escrever o que vemos com a novidade, e não ver e escrever o que pensamos com o já notado, o já dito. Expomos nossas palavras ao que está acontecendo. Estranhamos aquilo que se apresenta, pois, "sem estranhamento, sem perplexidade e, de certo modo, sem o desvanecimento do eu, não seria possível pensar, nem sentir, nem tocar a escrita. [...]. O que transborda é o incompreensível e o lugar de fragilidade é o lugar onde nos encontramos" (SKLIAR, 2014b, p. 131). Daí que as viagens sejam experiências de estranhamento, de que não levam a nenhum porto seguro, mas a lugares de extravio, de contrassenso, no umbral de nossas vidas, nos limiares da infância (FLORES, 2017).

Nesse fluxo, escrever no espaço do entre tem a ver com o fato de que, no caso, "não podemos invadir, colonizar ou povoar um território ou outro em nossas pesquisas [...], mas sim, de produzir um espaço e com ele criar zonas de deslocamento, ou seja, dito de outro modo, lugares de passagem" (LEITE, 2016, p. 95). O que significa, ainda, que para escrever o que nos passa no espaço do entre seria preciso apostar no mínimo e abandonar as grandes narrações, descrições e tentativas de chegar a algum lugar, a um resultado. Seria o caso, então, de um aproveitamento de materiais em tempo quase demolido, uma escrita com os restos de uma pesquisa em educação matemática? De uma pesquisa que relaciona arte com matemática, para ensinar matemática? Há ressonâncias. Há incitações no pensamento. Há ecos entre arte e matemática (FRANCISCO, 2017), “ou matemática entre arte, ou arte entre matemática, entretanto, martemática para pensar a educação matemática” (KERSCHER, 2017, p. 39).

No passo,

a criança nos convida a abrir, a fazer fugas, a quebrar "canos" do pensar. Nós nos quebramos. O "nós" minou-se todo. Talvez, alguma coisa que tenhamos a oferecer seja o mundo: um mundo de coisas (signos) a oferecer, mas que, de antemão, não seja significado, explicado, desdobrado, mas experimentado e, sobretudo, brincado. Apenas encontro. Puxando Benjamin: contrapelado no pensamento. Um pensamento de (no) fazer pensar ou fazer (conhecer coisas) de outro jeito - a ponto de experiência (FRANCISCO, 2017, p. 249, grifo do autor).

Assim, ao escrever, uma força que está à espreita passa por nossos corpos, que se mostram como territórios de passagem, uma superfície sensível no entre-tempo do acontecimento. $\mathrm{O}$ vento que vem em nossa direção encontra-nos abertos, dispostos a sentir a brisa em nosso rosto, peito, corpo, uma força que leva para além de nós mesmos. Nessa receptividade, disponibilidade, vulnerabilidade, ele inscreve marcas, deixa vestígios, nos faz outro.

Um olho desregulado é botado para preencher o espaço. (E isso lá poderia ser área? $\mathrm{O}$ que importa? O que porta a área?). Uma criança quis esconder o símbolo da camiseta com um olho e preencheu seu espaço - todo desregulado - com um olho e 
resolveu seu problema de esconder o símbolo. Basta botar alguma coisa em cima. Linhas retas e pontiagudas não têm muita visão nos "tipos de meus" das crianças. A forma geométrica é quase inutensílio. Mais vale juntar olhos e fazer um conjunto de olhos e bocas, e fazer um monte de bocas e cabelo, e uma montanha de cabelo, peças misteriosas com peças misteriosas [(Imagem 3)]. A forma em si não parece ser o sentido de uma estratégia, mas o signo de cada uma em conjunto separado, e que depois se desconjunta tudo junto (FRANCISCO, 2017, p. 229).

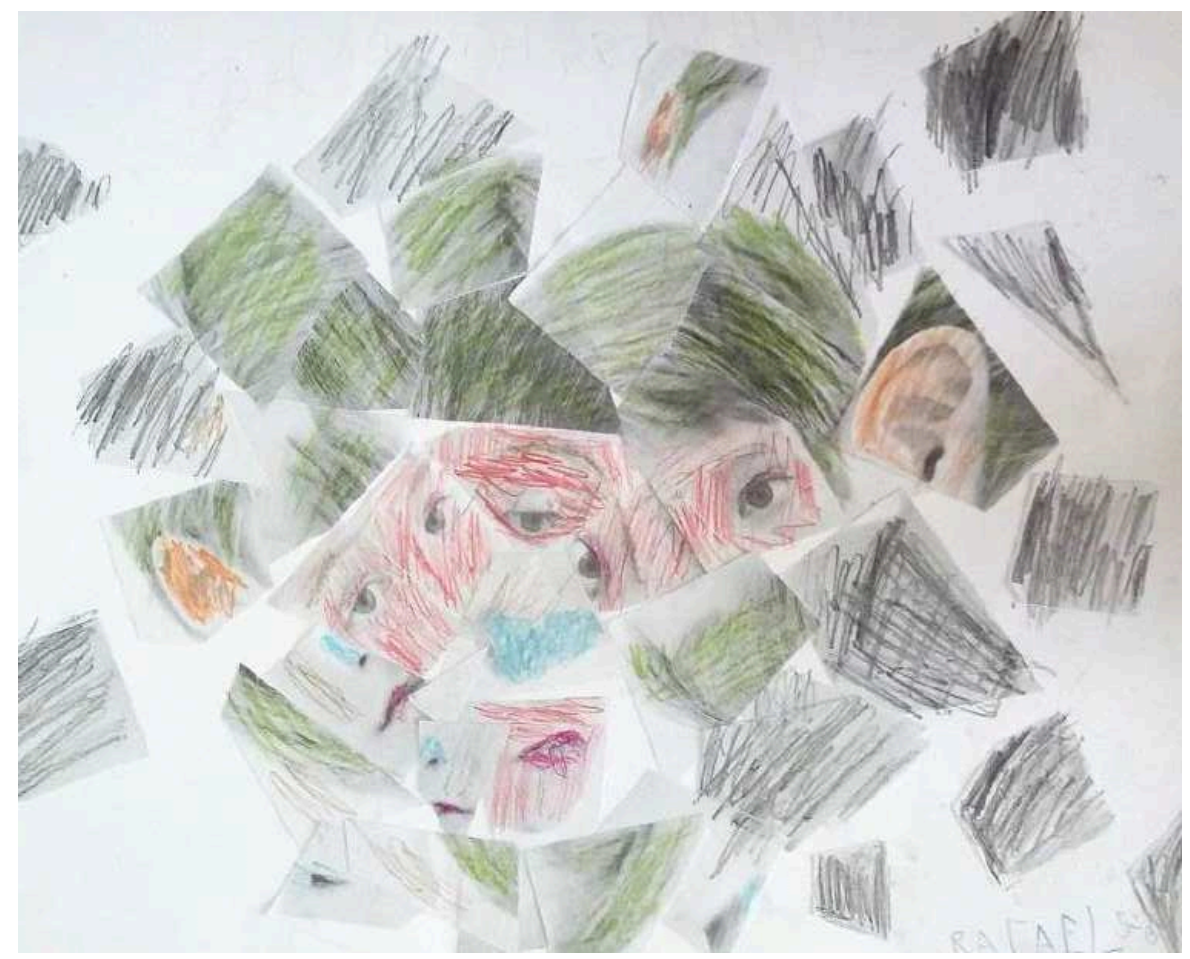

Imagem 3 - oficina-com-des-re-tra-tos: Fora da realidade.

Fonte: Francisco (2017, p. 184).

As crianças vão caminhando assim, oferecendo saídas para elas mesmas quando se encurralam, quando decidem não ser mais certinhas, que o olho atrás das costas é mais interessante.

E brincam...

Falam, depois de um, dois, três... (esmaecendo a voz).

Em uma grande roda deformada.

Dizem absurdos da vida.

Migalhas de uma matemática.

Que nem sequer tem nome.

Talvez tonta - uma matemática tonta (FRANCISCO, 2017, p. 229-230).

Que brinca. Brinca com os resíduos de um "canteiro de obras" (BENJAMIN, 2012, p. 17). Em um canteiro de obras tantas coisas podem ser pensadas e imaginadas. Tantas coisas podem ser feitas, criadas e inventadas com os resíduos da construção, do trabalho no jardim ou com os retalhos da costura e com a serragem e o cepilho da marcenaria...

"Migalhas de uma matemática.

Que nem sequer tem nome.

Talvez tonta - uma matemática tonta" (FRANCISCO, 2017, p. 230) que roda. Roda pela sala de aula, pela escola, pela rua, pela praça, pela vida. Tonteia. Aquela tontura de quando "criança que roda, roda e roda em torno de si mesma até ficar tonta e cair. Cair não é bom, mas a tonteira é deliciosa" (LISPECTOR, 1999, p. 57). São experiências que se 
inscrevem pelo meio, na processualidade, no entre as coisas, entre pulsações, entre rodopios. Nem pelo começo e nem pelo fim. Intermezzo. Meio que e onde pode nos dar o sentido mais vivente daquilo que se passa conosco e vibra, pulsa saberes (LARROSA, 2016). São afetos que pedem passagem na experiência que nos toca, intensidades que nos envolvem e nos potencializam pelo entre, no entre e com o entre. Travessia.

“- Eu não entendi nada! Qual o sentido disso? Da gente estar trabalhando matemática? - disse Anna" (KERSCHER, 2017, p. 83).

Anna insistia em saber o que a atividade tinha a ver com "a matemática", em saber qual seu início, meio e fim, tentando antecipar o resultado do que, possivelmente, se obteria com todas aquelas cores, formas e texturas. Insistia em saber o sentido, ou o sem-sentido, de se fazer uma forma geométrica com a sua cor favorita. Anna queria que estabelecêssemos para ela nosso sentido, nossa intensão, colocando-a no pensável do nosso pensamento, enjaulando-a no nosso saber de professores, de matemática, da matemática. No entanto, nessa atividade, "o sentido não é comunicado, mas comunica alguma coisa" (FLORES, 2017, p. 183, grifo da autora).

\footnotetext{
- Eu sei que formas geométricas têm a ver com matemática. [...] O centímetro do círculo? O lado do triângulo? [...] As formas geométricas costumam ter lados, e os lados dá para fazer, por vezes - continuou Anna.

- Geralmente, as formas geométricas têm um lado - concluiu Sara (KERSCHER, 2017, p. 83).
}

Portanto, “o que está em jogo, em ato, é uma produção, um pensamento. Então, pensar já não seria o bastante? Pensar não seria um tipo de aprendizagem que acontece experimentando formulações matemáticas, pensamento matemático?” (FLORES, 2017, p. 185).

Desta forma, pensamos e escutamos com as crianças, entre as crianças, com as artes, entre as artes, com a matemática, entre as matemáticas. Escutamos a nós mesmos, professores que ensinam matemática, que pesquisam matemática, crianças afetadas, infantes em devir. E se a matemática nos forma, nos racionaliza, nos dá poder e conhecimento, ela também nos atropela, nos invade, nos consome e nos cega. Mas com e entre as imagens e as crianças, a matemática pode ser outra coisa. Ela irrompe o espaço e é jogada com regras, mas sem regras. Ela explode e grita pedindo passagem por um diálogo de e entre crianças.

\footnotetext{
No manuseio dos objetos, na desorganização, no desespero de um corpo que não entra na ordem de sua mão, da folha, de seu pensamento, ou daquilo que nem sabemos que pensa. Na vontade de descontar o tempo, a matemática vai fugindo, fu gindo, fu gindo, fu gindo, fu gindo ... sem limite, estabelecendo-se na fronteira com a arte. A folha não tem limite. Ela pode ser alargada, ter coisas jogadas para fora, pedaços de papel recortados na dobra da folha. O espaço não é de todo medido, pensado, pois se espaça no achadouro de cada mão com um papel. A matemática, ou uma matemática sem nome, talvez tonta, vai se inventando na realidade tremida dos corpos despedaçados, sem normas, sem exercícios de medir, de identificação (FRANCISCO, 2017, p. 227).
} 
Aqui palavras que não correspondem a formas, à representação, mas palavras que apenas captam forças. Forças intensivas que remexem nossos pensamentos com o acontecimento, que se produzem no espaço do entre, na tensão dos movimentos concretos da pesquisa e que se operam na escrita. Uma escrita de pesquisa e uma pesquisa de escrita que, talvez, possam ser tomadas como ficções científicas,

\begin{abstract}
no sentido de que os pontos fracos se revelam. Ao escrevermos, como evitar que escrevamos sobre aquilo que não sabemos ou que sabemos mal? É necessariamente nesse ponto que imaginamos ter algo a dizer. Só escrevemos na extremidade de nosso próprio saber, nessa ponta extrema que separa nosso saber e nossa ignorância e que transforma um no outro. É apenas desse modo que somos determinados a escrever. Suprir a ignorância é transferir a escrita para depois ou, antes, torná-la impossível. Talvez tenhamos aí, entre a escrita e a ignorância, uma relação ainda mais ameaçadora que a relação geralmente apontada entre a escrita e a morte, entre a escrita e o silêncio. Falamos, pois, de ciência, mas de uma maneira que, infelizmente, sentimos não ser científica (DELEUZE, 1988, p. 18).
\end{abstract}

\title{
Referências ou as cores da escrita
}

BARROS, M. Memórias inventadas: a segunda infância. São Paulo: Ed. Planeta do Brasil, 2006.

BENJAMIN, W. Rua de Mão Única. Obras escolhidas, vol. 2. 6. ed. São Paulo: Brasiliense, 2012.

DELEUZE, G. Crítica e Clínica. São Paulo: Ed. 34, 1997.

DELEUZE, G. Diferença e repetição. Rio de Janeiro: Graal, 1988.

FLORES, C. R. In-fante e profanação do dispositivo da aprendizagem matemática.

Perspectivas da Educação Matemática, INMA/UFMS, v. 10, n. 22, seção temática, p. 171$188,2017$.

FRANCISCO, B. M. Um oficinar-de-experiências que pensa com crianças: matemáticascubistas, formas brincantes e exposições. Dissertação de Mestrado em Educação Científica e Tecnológica - Universidade Federal de Santa Catarina, Florianópolis, 2017.

GULLAR, F. Poesia completa, teatro e prosa. Rio de Janeiro: Nova Aguilar, 2008.

GULLAR, F. Toda poesia. Rio de Janeiro: José Olympio, 2015.

KERSCHER, M. M. Experimentação abstrata num espaço-escola-espaço e a matemática que percorre com crianças. Projeto de Dissertação em Educação Científica e Tecnológica no Programa de Pós-graduação em Educação Científica e Tecnológica, Florianópolis, 17 ago. 2017.

LARROSA, J. Tremores: escritos sobre experiência. Belo Horizonte: Autêntica, 2016.

LEITE, C. D. P. Arte e Pensamento. In: FLORES, M. B. R. et al. (Orgs.). Arte e Pensamento. Operações Historiográficas. São Paulo: Rafael Copetti Editor, 2016. p. 94-106. 
LISPECTOR, C. Um sopro de vida. Rio de Janeiro: Rocco, 1999.

MASSCHELEIN, J. E-ducando o olhar: a necessidade de uma pedagogia pobre. Educação e Realidade, v. 33, p. 35-48, 2008.

SKLIAR, C. Desobedecer a linguagem: educar. Belo Horizonte: Autêntica, 2014a.

SKLIAR, C. O ensinar enquanto travessia: linguagens, leituras, escritas e alteridades para uma poética da educação. Salvador: EDUFBA, 2014b.

\section{SOBRE OS AUTORES}

CLÁUDIA REGINA FLORES: Licenciada em Matemática pela Universidade Federal de Santa Catarina. Mestra e Doutora em Educação pela Universidade Federal de Santa Catarina. Pós-doutorado na Universidade da Carolina do Norte-EUA e na Universidade Católica de Lovaina-Bélgica. Professora Associada no Centro de Ciências da Educação, no Departamento de Metodologia de Ensino da Universidade Federal de Santa Catarina. Professora credenciada no Programa de Pós-Graduação em Educação Científica e Tecnológica da Universidade Federal de Santa Catarina. Professora Pesquisadora Produtividade CNPq.

MÔNICA MARIA KERSCHER: Licenciada em Matemática pela Universidade Federal de Santa Catarina. Mestra em Educação Científica e Tecnológica pela Universidade Federal de Santa Catarina. Doutoranda em Educação Científica e Tecnológica pela Universidade Federal de Santa Catarina.

BRUNO MORENO FRANCISCO: Licenciado em Matemática pela Universidade Estadual do Paraná. Mestre em Educação Científica e Tecnológica pela Universidade Federal de Santa Catarina. Professor da rede municipal de educação de Florianópolis em nível Fundamental e Médio. 